\title{
REBAJAMIENTO Y VULGARIZACIÓN DEL MITO: EL PAPEL DE LOS GRACIOSOS \\ EN LA FIERA, EL RAYOY LA PIEDRA DE CALDERÓN
}

\author{
Lavinia Barone \\ Dipartimento di Studi Umanistici \\ Facoltà di Lettere e Filosofia \\ Università degli Studi di Palermo \\ Viale delle Scienze, Edificio 12 \\ 90128 Palermo. Italia \\ laviniabarone@gmail.com
}

[Anuario calderoniano (ISSN: 1888-8046), 7, 2014, pp. 81-98]

En el contexto del paradigma dramático que conduce a la madurez del teatro calderoniano, la comedia mitológica participa del auge del teatro de corte en la España del siglo XVII y se caracteriza por tener una naturaleza plurisignificante, ya que su estructura puede considerarse como la perfecta unificación de diferentes lenguajes artísti$\cos ^{1}$, además de basarse en un conjunto de códigos dramáticos comunes tanto al universo de la dramaturgia calderoniana como a la

${ }^{1}$ Sobre esta caracterización de la comedia mitológica calderoniana ver Gentilli, 1991, pp. 23-24. 
de su tiempo ${ }^{2}$. En efecto, Calderón se conformó con escribir sus comedias mitológicas según los códigos dramáticos establecidos por las convenciones del género; en estas obras, aunado al cuidadoso e ingente despliegue del aparato escénico ${ }^{3}$, se encuentra también su fundamento ético y filosófico, puesto que la dimensión alegórica, el significado didáctico y la moralidad representan el núcleo ideológico esencial de estas piezas, junto al propósito serio que está al lado de su componente político y se manifiesta en el valor celebrativo de la realeza ${ }^{4}$.

Se suele fechar la composición de La fiera, el rayo y la piedra entre 1651 y 1652; en ocasión del cumpleaños de la reina Mariana de Austria, segunda esposa de Felipe IV, la obra se estrenó en el Coliseo del Buen Retiro en el mayo de 1652, probablemente con el título de Las durezas de Anajarte y el Amor correspondido 5 . La elaboración temática de la comedia se realiza a partir del principio de variedad, pues Calderón mezcla más fábulas y personajes mitológicos aun consiguiendo mantener la unidad de su obra y el perfecto equilibrio de las partes que la constituyen ${ }^{6}$. El libre manejo de las fuentes, su transformación e incluso la inserción de elementos nuevos confluyen en una narración mítica finalizada a la creación de un espectáculo teatral que sigue basándose en los esquemas característicos de la comedia calderoniana, sobre todo en lo perteneciente a la organización típica del enredo, puesto que, como subraya Egido, la representación de La fiera sugiere una lectura articulada en varios niveles que confluye en el principio de la armonía que triunfa sobre los conflictos, pues el desenlace final corresponde al restablecimiento del orden ${ }^{7}$.

${ }^{2}$ Como no es este el lugar para analizar detalladamente las características esenciales, las formas y las modalidades a través de las cuales se fue desarrollando la comedia mitológica calderoniana dentro del marco más amplio del teatro cortesano, se remite a los estudios de Arellano 2001, Chapman, 1954 y Díez Borque, 2003.

3 Sobre el uso de recursos escénicos para la representación de las comedias mitológicas calderonianas ver Maestre 1988. Para un desarrollo del asunto inherente a los significados simbólicos e ideológicos de la perspectiva teatral que caracteriza la representación de piezas cortesanas ver Amadei Pulice, 1991, y Neumeister, 1989.

${ }^{4}$ Greer, 1989.

${ }^{5}$ Sobre las representaciones de la obra y sus variantes ver Egido, 1989b.

${ }^{6}$ Para un recorrido de las fuentes de las que Calderón sacó temas y personajes para su comedia ver Egido, 1989a, pp. 53-63, y Valbuena Briones, 1965, pp. 336 y ss.

7 Egido, 1989a, pp. 54-56. 
La inserción de fábulas mitológicas obedece a dos asuntos muy conocidos de la tradición clásica: por un lado, el tema del destino despliega el problema de la intervención de los dioses en la vida mortal y la lucha entre voluntad divina y deseos humanos, cuyo símbolo en la escena puede reconocerse en la representación de las Parcas, y por otro aparecen el asunto del enamoramiento y su relación con el tema de la dicotomía entre amor rechazado y amor correspondido, escenificada a través del feroz enfrentamiento entre Cupido y Anteros.

Ciñéndonos a la readaptación de los mitos, es importante esbozar los aspectos básicos que caracterizan el contexto y los modos de difusión de la tradición mítica en la España de la edad áurea ${ }^{8}$.Ya a partir del siglo XVI, con la Genealogía de los dioses paganos de Boccaccio, todos los repertorios mitológicos solían servirse de la alegoría como elemento básico de interpretación, sometiéndose a los principios moralizantes de la tradición hermenéutica; entre ellos, destacan El libro de las diez cuestiones vulgares del Tostado, La filosofía secreta de Juan Pérez de Moya y el Teatro de los dioses de la Gentilidad de Baltasar de Vitoria. En la labor dramática de Calderón, dichos tratados representaban obras de consulta donde encontrar argumentos y personajes ya sometidos a un complejo tratamiento interpretativo a través de la alegoría, lo que constituía un punto de partida fundamental para la transmisión de ideas filosóficas, religiosas y morales. Al lado de estas obras — que se inscriben en la larga tradición de los compendios mitológicos ${ }^{9}$ - en la España del Siglo de Oro, las Metamorfosis de Ovidio gozaban de una larga difusión que se remontaba a los Ovidios moralizados de procedencia medieval ${ }^{10}$.

El uso de la mitología clásica en la fiestas calderonianas es funcional a la construcción del espectáculo, pues el libre manejo de las fuentes no solo permite disfrutar las referencias a fábulas y anécdotas conocidas por el público, jugando con su manipulación, sino que cumple también con el deber de alabanza y exaltación del poder, lo que cabe dentro del oficio de cada dramaturgo de corte tal y como era por entonces Calderón ${ }^{11}$. Además, el espectáculo de las comedias mitológi2002.

${ }^{8}$ Ver Álvarez Morán, 1976; Cossío, 1952; y Ponce Cárdenas y Colón Calderón,

9 Álvarez Morán e Iglesias Montiel, 1998.

10 Álvarez Morán, 1977.

${ }^{11}$ Ver Greer, 1991. 
cas se basa en un fondo ideológico cuyo origen se remonta a la estratificación de significados simbólicos y alegóricos que la tradición solía atribuir a la realeza y a sus representantes en el mundo.

La continua experimentación teatral que caracteriza la dramaturgia calderoniana afecta también a la construcción del papel risible y sus diferentes inserciones en obras que pertenecen a géneros diferentes; por estas razones, es fundamental analizar la presencia del elemento cómico dentro del sistema dramático que regula la construcción de la comedia mitológica calderoniana. Ateniéndonos a la presencia y a las formas de la risa en este marco dramático, es importante recordar que existe una "fuerte presencia de ingredientes burlescos, cercanos a la comedia de disparates y a los modelos de carnaval, que se integran, bien en el complejo del espectáculo cortesano, bien en la misma comedia» ${ }^{12}$; el ambiente palaciego pues permite a la comicidad expresarse dentro de unas fórmulas que por un lado no excluyen incluso los aspectos más burdos y violentos de la expresividad verbal y corporal, y por el otro admiten la ingeniosidad jocosa, los momentos lúdicos, la risa festiva y la burla como elemento fundamental que consigue desencadenar la acción dramática y a veces construir una espectacularidad capaz de expresarse también en cuadros de comicidad autónoma que subrayan la importancia estructural de la risa dentro de las dinámicas de la representación, produciendo la ruptura de la tensión dramática ${ }^{13}$.

Ciñéndonos al tema de la comicidad en La fiera, el rayo y la piedra, se van a analizar las principales funciones dramáticas desarrolladas por los personajes cómicos de la obra, y sobre todo se examinará su peculiar conexión con el fenómeno del rabajamiento y de la vulgarización del mito. Lo primero que destaca en la pieza es la proliferación de la graciosidad, ya que el complejo sistema de los personajes que caracteriza su construcción dramática se fundamenta también en la función trimembre de los graciosos que aparecen en la escena, Pasquín, Brunel y Lebrón, cuya naturaleza risible se manifiesta ya a partir del nombre, según un recurso bastante clásico de la comedia áurea.

12 Arellano, 1998, p. 73.

13 Sobre el despliegue de la comicidad y la tendencia burlesca en el teatro cortesano de la época ver Urzáiz Tortajada, 2006, pp. 11-13. 
Con respecto a la relación entre la construcción dramática de los graciosos y su interacción con el asunto mitológico de la pieza, destaca la función de degradación de la perspectiva reverencial hacia las divinidades y sus manifestaciones, actitud expresada por los personajes principales de la comedia y burlada por la ironía irrisoria de los graciosos. Este rebajamiento de temas y contextos graves al nivel de lo cotidiano y terrenal entra en la connotación tradicional del papel cómico; las intervenciones ridículas representan el contrapunto burlón y descarado de lo maravilloso y extraordinario, cualidades que pertenecen a la esfera del mundo divino y que el dramaturgo manipula a través de la parodia y de la vulgarización. La construcción de este personaje sigue las pautas de la codificación tradicional, y se expresa a través del típico antiheroísmo que contrasta la grandiosidad y el valor de los protagonistas, o con la caricatura de circunstancias graves y expresiones sublimes por medio de recursos lingüísticos cuya ingeniosidad verbal se funda en los presupuestos lógicos de la agudeza y del discurso ridículo ${ }^{14}$.

Para explicar las modalidades de inserción de los personajes cómicos y sus relaciones con el mundo de la mitología y sus manifestaciones en La fiera, vamos a centrarnos en algunos episodios significativos del drama y que están relacionados con sus motivos principales, es decir el tema del destino y la dimensión conflictiva del amor. En su aparición en la comedia, las Parcas anuncian el nacimiento de Cupido como la mayor ruina del mundo, que para los protagonistas va a ser fiera, rayo y piedra, enigmática explicación que tomará sentido al desarrollarse la acción. Las palabras de Lebrón y Brunel anticipan la aparición de las Parcas. Esta tradición mitológica tan arcaica, difundida a través de la Teogonía de Hesíodo (vv. 211-222), la República de Platón (X, 14-16) y la Eneida de Virgilio (X, 814), sigue perdurando en los discursos divertidos de los graciosos, aunque adquiriendo una faceta burlona que cumple con la función de degradación de la perspectiva reverencial hacia las divinidades.

LEBRÓN ¿Adónde que nos hallamos

dijo esa señora bestia?

14 Egido, 1989, pp. 73-75. 
BRUNEL

LEBRÓN
¿No lo oyes? A los umbrales

de las Parcas.

$$
\begin{aligned}
& \qquad \text { ¿No son esas } \\
& \text { unas beatas que, hilando } \\
& \text { siempre, nunca echaron tela } \\
& \text { y con ser tan hacendosas, } \\
& \text { jamás hacen buena hacienda? }
\end{aligned}
$$

$$
\text { (I, vv. 255-263) }{ }^{15}
$$

La alusión a la iconografía clásica de las Parcas le permite a Calderón construir la comicidad de sus personajes, ya que la mirada burlona y utilitaria de los graciosos ignora el aspecto sagrado de una actividad tan misteriosa e imprevisible y rebaja la dimensión mitológica a lo cotidiano, pues solo se fija en sus consecuencias más pragmáticas. En la perspectiva material y terrenal de los graciosos, el trabajo de las Parcas no tiene provecho, puesto que no consigue producir nada porque van hilando y cortando al mismo tiempo sin que de esta actividad consigan sacar las telas. Como ya apuntó Egido, la imagen de estas divinidades tiene cierta semejanza con el cuadro de Las hilanderas de Velázquez ${ }^{16}$, sobre todo por sus conexiones con ámbitos degradados y brujeriles, según una perspectiva "celestinesca» que relaciona el punto de vista de los graciosos con el de Ángel del Campo, quien considera a ese lienzo como una representación de la «alcahuetería como actividad provechosa ${ }^{17}$. En efecto, así reaccionan los tres al mirar las divinidades intentas a hilar:

PASQUín ¿Qué miedo pone el mirarlas!

BRUNEL ¡Y qué temor causa el verlas!

LEBRÓN A cuál temor y a cuál miedo es mayor, hago una apuesta.

Los Dos ¿Tanto te parece el tuyo?

LEBRón Tanto, que con ser tan puerca de las Hileras la calle, tomara estar ahora en ella,

${ }^{15}$ A partir de ahora, todas las citas procedentes de la comedia se refieren a su edición al cuidado de Egido, 1989.

16 Egido, 1989, pp. 37-42.

17 Ángel del Campo, 1983, p. 9. 
a trueco de no estar en

la gruta de las Hileras.

(I, vv. 317-326)

Estos versos revelan la esencia de la construcción dramática que caracteriza a los tres personajes, a partir de las marcas tradicionales del papel cómico: así, la alusión a la apuesta hecha por Lebrón nos permite colocarlo en la dimensión lúdica de lo cotidiano y dentro de un universo existencial centrado en la búsqueda continua del provecho. Además, el recurso al chiste y al juego lingüístico permite trocar los nombres de Parcas y "puercas», pero sobre todo el rebajamiento de la perspectiva mitológica de la fábula al nivel popular de los barrios de Madrid, una realidad ordinaria que corresponde a la calle de las Hilanderas, tal y como la representó Velázquez en su cuadro. A través del valor visual de la palabra teatral, Calderón incluso consigue presentar a los espectadores los lugares más ínfimos de las clases bajas, pues utiliza un recurso retórico que traduce la incursión de los espacios subalternos en la dimensión sublime de la sacralidad que corresponde al mundo de la realeza. La actitud desmitificadora del gracioso cumple con su función dramática sobre todo por lo que se refiere a la temática del enamoramiento y a los aspectos conflictivos del amor: efectivamente, el joven semblante de Cupido se presta muy bien a las burlas irreverentes de los graciosos que aprovechan la ocasión para reírse de la actitud presuntuosa del dios:

LEBRón Quitad de ahí, que es un rapaz

que apenas sabe a la escuela

y es, oliendo a las mantillas,

muy bello para ser fiera,

muy tibio para ser rayo,

muy blando para ser piedra.

(I, vv. 501-506)

Todo el mundo recuerda la iconografía clásica que la tradición ha mantenido durante siglos para representar a Cupido: sin hacer referencia a todas las fuentes, será suficiente conformarnos con los numerosos Emblemas de Alciato para identificar al dios como un niño alado, con arco y flechas, cuyas armas son capaces de someter a cualquiera, pues su poder llega a rendir hasta a los más fuertes. En estos 
versos, Lebrón se burla del semblante del dios hasta ridiculizar su edad tan tierna a través de alusiones groseras al olor de su mantilla. Las referencias a elementos indecentes y escatológicos es una de las características más frecuentes en los personajes risibles ya que, como teorizó Bachtin, la cultura cómica popular sobre la que se funda su construcción dramática, se alimenta de todas las expresiones del «realismo grotesco» ${ }^{18}$. Tanto en la representación de las Parcas como en la de Cupido, puede apreciarse el uso de un mecanismo paródico con respecto a la perspectiva ideológica relacionada con el mito, pues la profanación de lo sacro a través de la libertad expresiva llega a veces incluso a caricaturizar los atributos y el aspecto de las divinidades. Asistimos entonces a la transposición de los valores institucionales transmitidos por el mito a un nivel «bajo», material y pragmático que se remonta a las raíces carnavalescas del lenguaje cómico que consigue realizar el rebajamiento del mito según los principios de la lógica del mundo al revés. Así el materialismo se contrapone a la abstracción idealista que corresponde al sistema de los valores oficiales, puesto que el lenguaje cómico funciona como principio que permite la emancipación del dogmatismo religioso y de la oficialidad institucional. Gracias al perspectivismo dialógico se realiza, por lo tanto, la ruptura de la perspectiva unívoca y la abertura a la multiplicidad de los puntos de vista.

La parodia del enamoramiento a través de su vulgarización por el gracioso constituye un recurso escénico muy frecuente, sobre todo cuando la representación del amor y de las relaciones entre damas y galanes se caracterizan como expresión codificada de las costumbres cortesanas y de sus convenciones dramáticas. En las comedias mitológicas, el fundamento divino del enamoramiento adquiere más fuerza e importancia, puesto que tanto su función dramática como su presencia logran un grado máximo de abstracción gracias a la intervención de los dioses mitológicos, cuyo mundo llega a entremezclarse con el humano y cuya participación constituye un recurso escénico y diegético fundamental. Nos encontramos con una temática muy rica de pretextos para ser ridiculizada y parodiada por el gracioso, lo que en efecto sucede también en esta comedia, donde la presencia de tres divinidades vinculadas al amor (Venus, Cupido y Anteros) bien se pres-

18 Bachtin, 2001, p. 25. 
ta a la representación de un conflicto sentimental cuya tripartición entre las parejas protagonistas se refleja en la función trimembre de los graciosos.

Al cerrarse el acto primero, Cupido realiza su venganza dando lugar a un conflicto amoroso que envuelve a las tres parejas y que así comenta Lebrón:

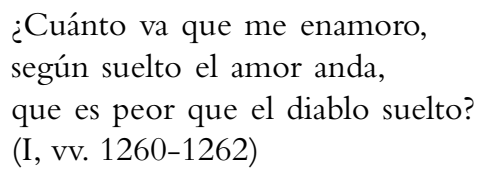

En su parlamento burlón, el gracioso ridiculiza el enamoramiento repentino de los demás por efecto de alguna potencia demoniaca relacionada con el amor, lo cual tiene cabida en el antiguo mito de Cupido, cuya fuerza irresistible se origina en la incapacidad de los seres humanos de reprimir la pasión. Más interesante resulta el punto de vista humorístico de Lebrón respecto a las raras manifestaciones de inquietud y tormento de Pigmalión, que en su opinión son efectos de esa enfermedad tan peculiar que es la locura de amor, algo que él también siente pero que describe a su manera a partir de las palabras de su amo:
[... ]esa inquietud que tienes
Es como otra que yo tengo.
Desde aquel infausto día (¡quién le borrara del tiempo!) que en la fragua de Vulcano nos vimos todos revueltos, también tengo yo mi poco de no sé qué que le siento no sé donde y no sé cuándo le he de aplicar el remedio. (II, vv. 1636-1675)

Las palabras del gracioso representan una burla de toda la casuística de amor y sobre todo de su transposición lírica a través de recursos lingüísticos, temáticos y expresivos convencionales que se encuadran tanto dentro del marco literario y filosófico del conocido tópico 
neoplatónico del enamoramiento, como en el ámbito de su representación dramática en el teatro áureo ${ }^{19}$. Lebrón mantiene la misma actitud paródica hacia los efectos del enamoramiento durante toda la comedia, llegando incluso a la paradoja, como en el caso siguiente, donde Calderón inserta al gracioso en el contexto dramático de un diálogo con cuatro mujeres que, aunque construido sobre los presupuestos temáticos del amor cortés, se sirve de su rebajamiento ridículo y consigue provocar la risa no solo por su carácter absurdo sino por desvelar los mecanismos convencionales que sustentan este topos.

Destacan la ingeniosidad verbal y el uso de la ambigüedad, dos recursos que responden al propósito de contrastar con el estilo lírico y apasionado que suele connotar las palabras de los enamorados:

$\begin{array}{ll}\text { LEBRÓN } & {[\ldots] \text { ¿sabránme decir ustedes }} \\ \text { porque me importa saberlo, } \\ \text { cuál de ustedes cuatro es } \\ \text { una dama a quien yo quiero, } \\ \text { como cosa de perder } \\ \text { por ella el entendimiento? } \\ \text { Porque yo bien sé que es una, } \\ \text { más qué una es, no sé. }\end{array}$

ISABEL

estilo de declarar

¡Bien nuevo

un galán su sentimiento!

LEBRón Cada uno se declara como puede.

(II, vv. 1938-1948)

La caricatura hecha por Lebrón está escenificando una parodia del enamoramiento, rebajando las formas y los conceptos del diálogo amoroso al nivel burlón que caracteriza el lenguaje del gracioso. Además, puede apreciarse el recurso a la ironía metateatral que se funda en el concepto de "melancolía» como enfermedad del alma y que se manifiesta en la referencia ingeniosa a las palabras pronunciadas por Fénix

19 Sobre el tratamiento del tema del amor en el teatro cortesano español del siglo XVII, se remite a Sabik (2001), quien analiza este aspecto en los dramaturgos de la escuela calderoniana. 
en El príncipe constante, «Solo sé que sé sentir, lo que sé sentir no sé, que ilusión del alma fue» (I, 53-55) ${ }^{20}$.

Asimismo, a la pregunta de Laura sobre cuáles efectos de amor Lebrón piensa tener, contesta el gracioso:

En que ando más

limpio, en que hablo más discreto

que solía, y en que traigo

una hipocondria acá dentro

en traje de cosicosa

que la siento y no la siento.

(II, vv. 1952-1957)

La clave para entender el sentido más profundo y humorístico de estas palabras reside en la construcción convencional del papel risible tal y como le conocían los espectadores; además, la referencia irónica a la hipocondría constituye un recurso cómico muy frecuente, cuyo blanco es casi siempre el estado anímico de los enamorados parecido a una enfermedad indefinida que a veces roza incluso la locura. La función desmitificadora de Lebrón con respecto al enamoramiento de Pigmalión solo puede entenderse si se considera como parodia del mito al que se refiere. Una vez más, son las Metamorfosis de Ovidio (X, 243-297) la fuente a la que recurre Calderón para construir la narración mítica de su obra: según cuenta la fábula, Pigmalión se había enamorado de una estatua hasta perder la razón y considerarla su ideal femenino, pues su carácter misógino le mantenía lejos de las mujeres reales por no confiar en ellas. Para subrayar con ironía lo absurdo de esta pasión, Calderón construye el discurso ridículo de Lebrón utilizando el recurso retórico de la paradoja que incluso le permite al gracioso sacar algo conveniente de esta locura, según su tradicional opinión misógina que le hace despreciar a las mujeres y burlarse del comportamiento y de las costumbres que ellas suelen adoptar en la vida conyugal. A partir de la lógica al revés que sustenta la validez de su razonamiento, Lebrón justifica el enamoramiento de Pigmalión e incluso lo considera razonable; por supuesto, se trata de una perspectiva basada en la inversión, cuya función esencial consiste en revelar

${ }^{20}$ Sobre el significado de la melancolía en la construcción del personaje de Fénix se remite a Cancelliere, 2000, pp. 70-78. 
el contrasentido de una relación tan singular y lo absurdo de esa pasión:

Lebrón Porque quien no sabe hablar, no sabrá pedir. ¿Hay cosa más descansada que amanecer uno sin cuidar de lo que su dama ha de comer y vestir? Y más en tiempo que el traje está tal, que sin mentir, no se usa por mayo el jubón que se hizo en abril. Fuera de que ¿qué reposo puede haber como dormir seguro de que su dama en casa está?

(II, vv. 2192-2205)

La mirada burlona del gracioso saca del mito todos los elementos básicos para desacralizar su valor alegórico y rebajar el significado profundo de la fábula y su lectura moralizada, según la cual la virtud y la constancia mostradas por el joven le permitirán realizar sus deseos, pues la pureza del sentimiento amoroso y el rechazo de los aspectos más terrenales de la pasión representan el justo camino que es necesario seguir.

Además, el desposorio de la estatua constituye un tema muy frecuente en la tradición clásica y aquí cobra más importancia por referirse al asunto mitológico que sustenta la construcción dramática del personaje de Pigmalión ${ }^{21}$; por supuesto, Calderón somete también esta temática a la ironía de Lebrón quien se burla de su amo escenificando incluso un diálogo con la estatua:

LEBRón ¿Cómo me he de ir, sin saber si ha venido muy cansada, aunque no ha venido a pie, doña Mármol, mi señora?

Sea bien venida usted

21 Olmos, 1992. 


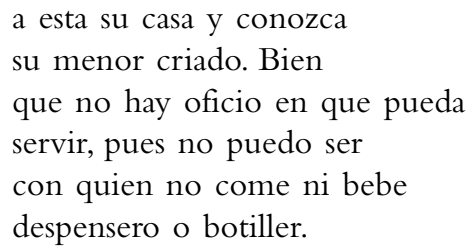

Según los principios de la economía identificativa, en muy pocos versos, Lebrón escenifica los valores que fundamentan la construcción tradicional de su papel dramático a través de una clara alusión a su función de criado aficionado a los placeres terrenales y sobre todo al vino; sin embargo, por medio de la ironía, el gracioso se burla incluso de sí mismo, ya que su oficio roza la anulación por encontrarse al servicio de un ser desanimado y sobre todo sin necesidades. Vuelve otra vez el plan material de la existencia que corresponde a la dimensión orgánica simbolizada por las exigencias del cuerpo que ya no es una entidad monolítica sino espacio de confin. El cuerpo se transforma en lugar abierto que puede atraversarse porque está sumergido en el divenir continuo de la vida, una dimensión colectiva de condivisión que se funda en la realidad material y cotidiana de los instintos y de las necesidades, un mundo terrenal simbolizado por el gracioso que se contrapone a la naturaleza inanimada del mármol.

El gracioso es el primero en asistir a la transformación de la estatua en mujer, enterándose aún antes del mismo Pigmalión, ocupado en socorrer a Anajarte que está despeñándose del monte:

LEBRón Perdone vuesa merced, que es mi amo un caballero con las damas muy cortés, y así el socorrer a otra aire y no desaire es. ¿No lo siente usted así?

ESTATUA

LEBRÓN

ESTATUA

LEBRÓN
Sí.

¡Cielos! ¿Qué llego a oír y ver? ¿que no tiene celos?

No.

Ya va hablando un si es no es. Mi señora doña Mármol, 


\section{yo no enternezco a vusted y ansí no gaste conmigo finecitas de oropel.}

(III, vv. 3720-3732)

Una vez más, la comicidad verbal que sustenta el discurso del gracioso se funda en el empleo de la ingeniosidad lingüística: el uso chistoso de epítetos y de fórmulas de cortesía inapropiados por ser dirigidos a la estatua pertenecen a los recursos clásicos de la dramaturgia áurea empleados para provocar la risa, tal y como el juego de palabras entre "aire» y «desaire», o la alusión misógina a la costumbre femenina de fascinar a los hombres con finezas, recurso que se une muy bien al contexto de la narración mítica, pues se refiere al poder enternecedor de las lágrimas de Pigmalión que, según la fábula de Ovidio, conmovieron a la diosa Afrodita y consiguieron ablandar el frío marfil hasta que la estatua cobró vida. Pero hay más: en La fiera, la función desmitificadora del gracioso respecto a la tradición autoritaria del mito llega a expresarse también a través la ironía metateatral cuyo efecto se realiza en la ruptura de la ilusión escénica. Tras la transformación de la estatua en mujer y, al revés, la metamorfosis de Anajarte en mármol como consecuencia de su obstinación en rechazar el afecto de Ifis ${ }^{22}$, Lebrón así sintetiza el mensaje moral de la pieza y la exhortación a no quedarse sordos a la fuerza del amor:

$\begin{array}{ll}\text { LEBRÓN } & \text { Ojo a la margen, señoras, } \\ & \text { y tratadme de querer, } \\ & \text { si no quieren ser mañana } \\ & \text { todas de mármol. }\end{array}$

$$
\text { (III, vv. 3851-3854) }
$$

Algo similar puede afirmarse a propósito de la adaptación del mito de Anajarte a las exigencias dramáticas de La fiera; en efecto, según cuenta Ovidio (Met. XIV, 698-771), la obstinada dureza de la joven y su indiferencia hacia el rendimiento del enamorado, no le dejaron a Ifis otra solución que no fuese el suicidio. Afrodita, entristecida por su muerte, provocó la metamorfosis de la doncella en estatua ya que su

22 Sobre la tradición del mito de Anajarte y su transmisión de la antigüedad a Calderón véase Cristóbal López, 1996. 
corazón era tan duro y frío como el mármol. A las quejas de Ifis por la transformación de Anajarte, así contesta Brunel:

BRUNEL No has negociado mal, pues condenado a ahorcar estabas.

(III, vv. 3962-3964)

Su ironía solo puede comprenderse si se tiene en cuenta el destino trágico que el personaje de Ifis tenía según el mito y que, con mucha probabilidad el público bien conocía por la larga difusión de las fábulas mitológicas en la cultura del Siglo de Oro y por su frecuencia en las artes del tiempo. Las palabras de Brunel consiguen romper la ilusión dramática de la representación, pues van a desenmascarar la realidad ilusoria de la ficción jugando tanto con los códigos teatrales como con el sistema literario de referencias al mito relatado por Ovidio.

En conclusión, tanto la construcción dramática del papel risible como su inserción en las dinámicas de La fiera responden bien a las convenciones teatrales de la comedia nueva bien a los principios de la poética calderoniana, pues la risa se inserta con coherencia en el contexto del drama, respetando las leyes del decoro impuestas por la preceptiva de la época y aplicadas al ámbito del teatro de corte. Junto a las funciones más peculiares del personaje cómico, la comedia mitológica disfruta de las potencialidades expresivas del gracioso para ridiculizar tanto los procedimientos como las temáticas relacionados con el mito, sobre todo por lo que se refiere al rebajamiento de la perspectiva reverencial hacia lo divino que caracteriza a los personajes principales.

El gracioso sigue connotándose como figura vinculada a la dimensión material y terrenal de la existencia, lejos del espacio ideal que caracteriza la realidad sublime del mundo mítico. El carácter polifónico del discurso cómico, además, lleva al escenario la ruptura de la perspectiva unívoca y reverencial relacionada con el mito, disfrutando las potencialidades expresivas de la parodia que se funda en el principio de la ambivalencia y determina no solo el rebajamiento cómico de la realidad "oficial», sino también su dislocación, ya que descompone su valor para volver a organizarlo en el contexto bajo y terrenal que corresponde al mundo del gracioso. El lenguaje carnavalesco del papel risible se presta a la subversión de las jerarquías institucio- 
nales que organizan y garantizan el equilibrio del orden preestablecido y que, en el escenario de la comedia mitológica, confluye en la imagen del mito y en sus manifestaciones. 


\section{Bibliografía}

Álvarez Morán, M. ${ }^{a}$ C., El conocimiento de la mitología clásica en los siglos XIV al XVI, Madrid, Universidad Complutense, 1976.

- «El Ovide Moralisé, moralización medieval de las Metamorfosis», Cuadernos de Filología Clásica, 13, 1977, pp. 9-32.

- y R. M. ${ }^{a}$ Iglesias Montiel, "Los manuales mitológicos del Renacimiento», Auster, Revista del Centro de Estudios Latinos, 3, 1998, pp. 83-89.

Amadei Pulice, M. ${ }^{a}$ A., «Realidad y apariencia. Valor político de la perspectiva escénica en el teatro cortesano», Calderón: actas del Congreso Internacional sobre Calderón y el teatro español del Siglo de Oro, ed. L. García Lorenzo, Madrid, Centro Superior de Investigaciones Científicas, 1983, vol. III, pp. 1519-1532.

Arellano, I., «El teatro cortesano en el reinado de Felipe III», Cuadernos de teatro clásico, 10, 1998, pp. 55-73.

— «La comedia mitológica de Calderón», en Calderón de la Barca, El monstruo de los jardines, ed. J. Mayorga, Madrid, Editorial Fundamentos, 2001, pp. 9-28.

Bachtin, M., L'opera di Rabelais e la cultura popolare: riso, carnevale e festa nella tradizione medievale e rinascimentale, Torino, Einaudi, 2001.

Calderón de la Barca, P., El príncipe constante, ed. E. Cancelliere, Madrid, Biblioteca Nueva, 2000.

- La fiera, el rayo y la piedra, ed. A. Egido, Madrid, Cátedra, 1989.

Cancelliere, E. (ed.), Pedro Calderón de la Barca, El príncipe constante, Madrid, Biblioteca Nueva, 2000.

Chapman, G., «Las comedias mitológicas de Calderón», Revista de Literatura, 9-10, 1954, pp. 35-67.

Cossío y Martínez Fortún, J. M. , Fábulas mitológicas en España, Madrid, Espasa Calpe, 1952.

Cristóbal López, V., "Anaxárate, de Ovidio a Calderón», en De Roma al siglo xx, ed. A. M. Aldama Roy, Madrid, UNED, 1996, vol. 2, pp. 689-696.

Del Campo y Francés, Á., «La trama de Las Hilenderas», Traza y Baza, 8, 1979, pp. 5-19.

Díez Borque, José M. ${ }^{\text {, }}$, Teatro y fiesta del Siglo de Oro en tierras europeas de los Austrias, Madrid, SEACEX, 2003.

Egido, A. (ed.), Pedro Calderón de la Barca, La fiera, el rayo y la piedra, Madrid, Cátedra, 1989a.

- «Dos variantes escenográficas de La fiera, el rayo y la piedra de Calderón de la Barca», en Sobre poesía y teatro. Cinco estudios de literatura española, ed. C. Cuevas, Málaga, UNED, 1989b, pp. 73-93.

Gentilli, L., Mito e spettacolo nel teatro cortigiano di Calderón de la Barca. Fortunas de Andrómeda y Perseo, Roma, Bulzoni, 1991. 
Greer, M., "Art and Power in the Spectacle Plays of Calderón de la Barca», Publications of the Modern Languages Association of America, 104, 1989, pp. 329-339.

- The Play of Power: Mythological Court Dramas of Pedro Calderón de la Barca, Princeton, Princeton University Press, 1991.

Maestre, R., «La gran maquinaria en comedias mitológicas de Calderón de la Barca», en El mito en el teatro clásico español, coord. F. Ruiz Ramón y C. Oliva, Madrid, Taurus, 1988, pp. 55-81.

— «Calderón de la Barca-Baccio del Bianco: un binomio escénico», Revista de Historia moderna. Anales de la Universidad de Alicante, 11, 1992, pp. 23950 .

Neumeister, S., «Escenografía cortesana y orden estéticopolítico del mundo", en La escenografía del teatro barroco, ed. A. Egido, Salamanca, UIMP, 1989, pp. 141-159.

Olmos, R., «El amor del hombre con la estatua: de la Antigüedad a la Edad Media", en Kotinos. Festschrift für Erika Simon, ed. H. Froning, T. Holscher y H. Mielsch, Mainz, Verlag Philipp von Zabern, 1992, pp. 256-266.

Ponce Cárdenas, J. e I. Colón Calderón (eds.), Estudios sobre tradición clásica y mitología en el Siglo de Oro, Madrid, Ediciones Clásicas, 2002.

Urzáiz Tortajada, H., «El desvergonzado en Palacio: los graciosos de las comedias mitológicas», Acotaciones: Revista de Investigación Teatral, 17, 2006, pp. 9-44.

Valbuena Briones, Á., Perspectiva crítica de los dramas de Calderón, Madrid, Rialp, 1965. 